\title{
Making sense of place in community gardens in Urban Land- scape of Mexico City
}

1 Instituto Politécnico Nacional, Centro Interdisciplinario de Investigaciones y Estudios sobre Medio Ambiente y Desarrollo, Mexico City, Mexico; gmunguiau1800@alumno.ipn.mx

2 Instituto Politécnico Nacional, Centro Interdisciplinario de Investigaciones y Estudios sobre Medio Ambiente y Desarrollo; Mexico City, Mexico; pgutierrezy@ipn.mx

* Correspondence: gmunguiau1800@alumno.ipn.mx

\begin{abstract}
Our objective was to analyze the influence of place attachment at the individual level to build new urban landscapes. We explore the attitudes and social networks built from the voluntary participation in the management of two urban community vegetable gardens installed in Mexico City. The results revealed positive attitudes of the people towards the community gardens, due to the social ties built, the contact with the green spaces, and the activities carried out in them. It is worth noting that the abandoned spaces have been rebuilt through voluntary participation and collaboration with local authorities. We concluded that the participants developed a sense of place that contributed to the redesign of some places in their neighborhood and the preservation of the urban landscape.
\end{abstract}

Keywords: identity; community gardens; placemaking

\section{Introduction}

The landscape is, in general, the interaction between nature and the human being within a territory. People perceive and transform the environment around them, create bonds with the place and the people who live there; is a dynamic relation between human- nature. Also, the people of the place are objects and subjects of the landscape at the same time, and both people and territory are constantly changing [1]. Hence, the landscape is a multidisciplinary concept in which different perspectives are exchanged to understand the territory and the processes that occur there. Arts [2] identify four dimensions of the landscape: ecological, political, economic, and sociocultural, the latter comprises spaces as significant places, configured by a dynamic interaction between human-nature; relationships can be understood under the concept of sense of place by describing them, observing how they are built and how they are experienced.

Community gardens are a clear example of interaction between people and small green landscapes in urbanized environments. These gardens, in addition to being green recreational areas, function as if they were urban vegetable gardens, where people grow plants and carry out gardening activities [3,4]. In addition, its participants interact in the place and with the elements that compose it, create social networks, exchange knowledge, express their identity and build links in new communities [5-8]; furthermore, these spaces are managed by volunteers, who supervise their maintenance, this contributes to developing positive emotional experiences [9].

Green areas are always scarce in megacities, such as México City. Vegetable gardens represent alternatives to green areas and favor the opportunity to encourage participation through the appropriation of spaces. In this research, we aimed to analyze the influence of place attachment at the individual level to construct new urban landscapes; to carry out the objective we applied an attitude questionnaire and developed a focus group 
and interviews. We to display the results of part of an investigation carried out within different community gardens of the municipality Cuauhtémoc, Mexico City. The research questions were: 1) How do the volunteers perceive the community garden? and, 2) What activities promote attachment to the place?

\section{Area of study}

The study was carried out in two community gardens in the municipality of Cuauhtémoc (Center of Mexico City). Cuauhtémoc has 545,884 residents in a territory of $32.44 \mathrm{~km}^{2}$, which gives a population density of the highest in the world $(16,828$ inhabitants $/ \mathrm{km}^{2}$ ). To this crowd must be added the transit population that can easily exceed the resident population given that the Center of Mexico City is still the economic engine of the city, especially for the middle class and popular sectors. In this municipality there are tourist and cultural areas of more than 700 years, it was the founding site of the Greater Tenochtitlán, later called Mexico City. It is connected through a wide network of public transport, pedestrian street, and bicycle accesses. On the other hand, parks and gardens represent only $3 \%$ of the territory [10]. Because of the great deficit of green areas, community vegetable gardens represent alternatives to public green spaces. However, the creation of urban vegetable gardens in Mexico City is recent and there is no official count of these places. To illustrate, in the background of this study, we identified 13 community vegetable gardens within the municipality of Cuauhtémoc through requests for information to the National Institute of Transparency, Access to Information and Protection of Personal Data in conjunction with the snowball statistical method to know how much people know about their locality (Figure 1).

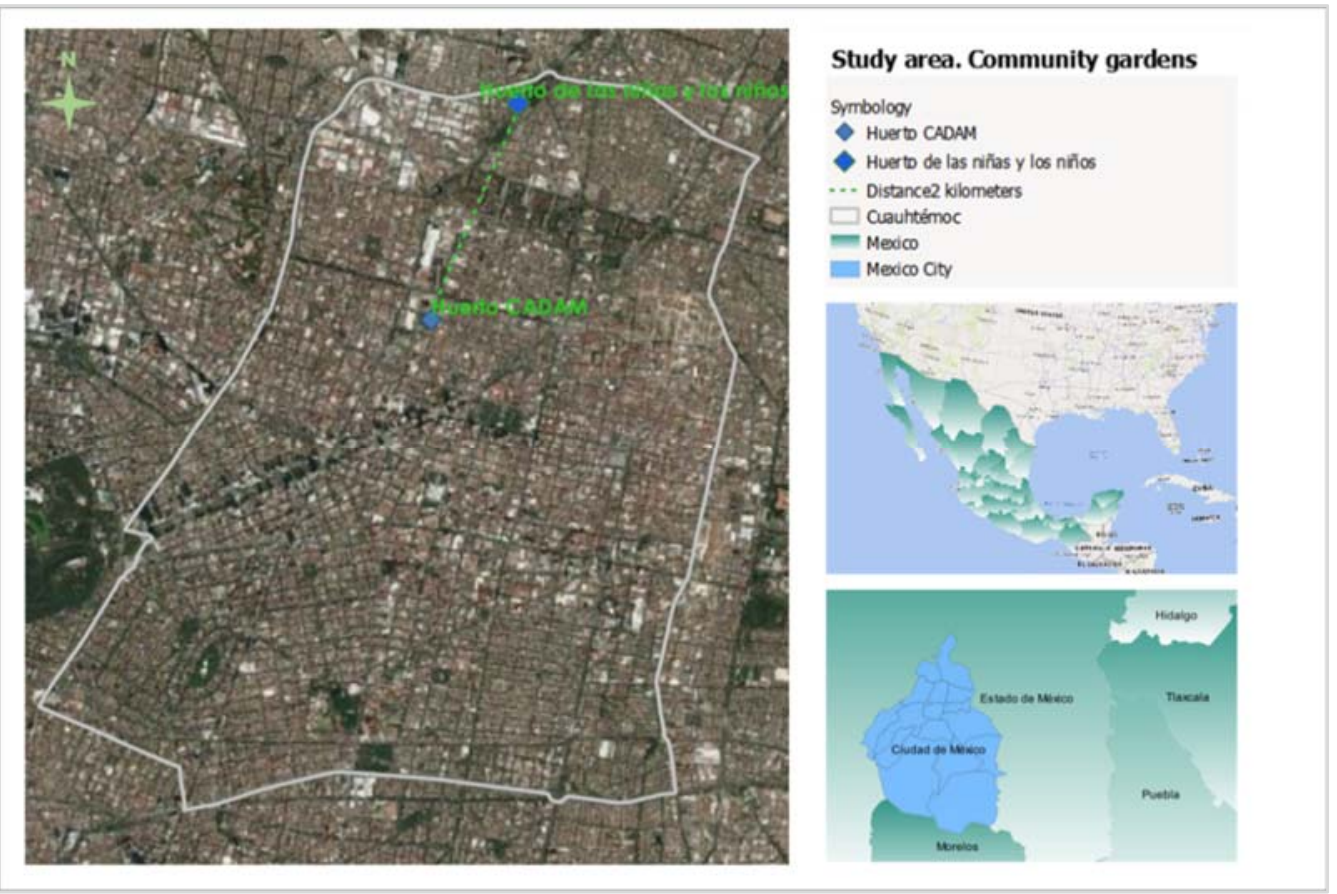

Figure 1. Community gardens within municipality of Cuauhtémoc

\subsection{Huerto de las niñas y de los niños}

We selected two of urban gardens within the municipality Cuauhtémoc to interview their participants: Huerto de las Niñas y de los Niños y Huerto CADAM. Community garden Huerto de las niñas y de los niños is in San Simón Tolnahuac neighborhood, on Insurgentes avenue. It has a length of around 190 meters. Since 1985, it has functioned as a social place, where the children were taught to plant vegetables and some native trees. Local authorities, who appoint a manager, carry out maintenance; however, the garden 
participants adopt one or more plots, which they maintain. Nonetheless, since the pandemic of COVID-19, the number of volunteers decreased, and direct employees of Cuauhtémoc mayor's office take over the garden. The inputs that the community garden receives are from the local government, as well as donations and exchanges between residents of other municipalities and from areas surrounding Mexico City. In addition, diverse kinds of resources have been obtained through calls launched by the local government.

\subsection{Huerto CADAM}

This community vegetable garden is located within Centro de Atención y Desarrollo del Adulto Mayor (CADAM), located in Buenavista neighborhood, in Cuauhtémoc. It is a space that emerged in 2019 and is managed by female volunteers over 50 years of age. The resources that the community garden receives are donations from other people who are not members of the urban garden and the participants themselves, who have cleaned and rehabilitated the space. Two years ago, when they received the area to build an urban vegetable garden, it could not be sown, the land was not in optimal condition; so, they created compost has been used to improve soil conditions.

\section{Methodology}

This exploratory research is cross-sectional. The methodological design was developed characterized by collecting, integrating, and analyzing quantitative and qualitative data [11]. The methodology was based on mixed methods: a Likert scale survey, interviews, and focus groups. Qualitative data were analyzed by Grounded Theory, which implies an inductive coding process in which the data is examined, codes are generated, and these are refined, finally, categories are created until saturation of the data is generated [12]. The information obtained in the questionnaires was analyzed through descriptive statistics.

\subsection{Sampling}

We use the snowball method to apply the Likert scale questionnaires; we have obtained the response of 18 volunteers, who are participating in or has been participating in a garden within the Cuauhtémoc municipality. For the focus group work and the interviews, we selected Huerto de las Niñas y de los Niños y Huerto CADAM. Due to sanitary conditions derived from the pandemic generated by SARS-COV 2 virus, we conducted interviews and focus groups via ZOOM. Attitude questionnaires were applied through Google Forms. This test pilot was applied between June and August 2021.

\section{Results}

\subsection{Descriptive statics}

The attitude questionnaire was shared by the community gardens organizers and local officials through What's app groups and Facebook. Respondents were mainly female (72\%); 39\% lives within Cuauhtémoc; $28 \%$ have been participated between two and three years ago; $22 \%$, since seven and eight years ago. Only $20 \%$ travel 10 minutes from their house to the garden; $62 \%$ live further away.

\subsection{Social and natural networks}

Following results to the question "I like to participate in the activities that take place in the vegetable garden", 95\% answered agree with this sentence. Among the reasons they enjoy being in the garden are to learn about plants, insects, and animals, also because they learn to grow their food. About social networks, $90 \%$ affirmed that they felt happy if spend their time with other participants. The participants indicate that they like to be in contact with nature through the garden and believe that the garden is a natural space. Volunteers also reported feeling happy and relaxed when they were in the garden. 


\subsection{Identity and place attachment}

We observed that community gardens are sites where participants can reflect on part of themselves. For example, $95 \%$ of answers agree with the sentence "I like to grow food that reminds me of my traditions". In addition, they perceived that the crops reflect the preferences of their participants. On the other hand, $90 \%$ answered feel proud to be part of the garden. Through the coding of the interviews, we identify codes related to the identity variable: learning, self-esteem, inheritance, pride, and social networks, the latter is related to attachment to place.

\section{Conclusions}

Through social networks and activities carried out on-site, participants of the community vegetable garden strengthen their attachment to the place. They feel proud to belong to this place and they identify themselves with the elements of the urban garden.

Attitudes towards the material garden, that is, the physical elements of the garden, are positive. The location of the garden is accessible to them, although some live five kilometers away. Gardens are also spaces that promote learning while volunteers learn from the place and when interchange knowledge with others. These attitudes positively facilitate gardening and maintenance activities necessary to preserve community gardens.

Funding: This research was funded by CONACYT and PROYECTO BEIFI grant number 20212009. Conflicts of Interest: The authors declare no conflict of interest. 